\title{
Mechanisms of Withdrawal-Associated Increases in Heroin Self-Administration: Pharmacologic Modulation of Heroin vs Food Choice in Heroin-Dependent Rhesus Monkeys
}

\author{
S. Stevens Negus* ${ }^{*, 1,2}$ and Kenner C Rice ${ }^{3}$ \\ 'Department of Pharmacology and Toxicology, Virginia Commonwealth University, Richmond, VA, USA; ${ }^{2}$ Alcohol and Drug Abuse Research \\ Center, McLean Hospital-Harvard Medical School, Belmont, MA, USA; ${ }^{3}$ Chemical Biology Research Branch, National Institute on Drug Abuse and \\ National Institute on Alcohol Abuse and Alcoholism, National Institutes of Health, Department of Health and Human Services, Bethesda, MD, USA
}

\begin{abstract}
Opioid withdrawal can produce a constellation of physiological and behavioral signs, including an increase in opioid self-administration. Different mechanisms mediate different withdrawal signs, and the present study used pharmacologic tools to assess mechanisms underlying withdrawal-associated increases in opioid reinforcement. Five rhesus monkeys were rendered heroin dependent via daily $2 \mathrm{I}-\mathrm{h}$ heroin self-administration sessions. One hour after each heroin self-administration session, monkeys chose between heroin $(0-0.1 \mathrm{mg} / \mathrm{kg}$ per injection) and food (I g pellets) during 2-h choice sessions. Under these conditions, heroin maintained a dose-dependent increase in heroin choice, such that monkeys responded primarily for food when low heroin doses were available (0-0.0 I mg/kg per injection) and primarily for heroin when higher heroin doses were available $(0.032-0.1 \mathrm{mg} / \mathrm{kg}$ per injection). Periods of spontaneous withdrawal were intermittently introduced by omitting one 21 -h heroin self-administration session, and test drugs were administered during these withdrawal periods. Untreated withdrawal robustly increased heroin choice during choice sessions. Withdrawal-associated increases in heroin choice were completely suppressed by the mu opioid agonist morphine $(0.032-0.32 \mathrm{mg} / \mathrm{kg} / \mathrm{h}$, i.v.), but not by the $\alpha-2$ noradrenergic agonist clonidine $(0.01-0.1 \mathrm{mg} / \mathrm{kg} / \mathrm{h}$, i.v. $)$, the dopamine $/$ norepinephrine releaser amphetamine $(0.032-0.1 \mathrm{mg} / \mathrm{kg} / \mathrm{h}$, i.v. $)$, or the $\kappa$-opioid antagonist $5^{\prime}$-guanidinonaltrindole $(1.0 \mathrm{mg} / \mathrm{kg}$, i.m.). The corticotropin-releasing factor I antagonist antalarmin $(1.0-10 \mathrm{mg} / \mathrm{kg}$ per day, i.m.) produced a morphine-like suppression of withdrawal-associated increases in heroin choice in one of three monkeys. These results suggest that mechanisms of withdrawal-associated increases in the relative reinforcing efficacy of opioid agonists may be different from mechanisms of many other somatic, mood-related, and motivational signs of opioid withdrawal.
\end{abstract}

Neuropsychopharmacology (2009) 34, 899-9| I; doi:I0. I038/npp.2008. I27; published online I3 August 2008

Keywords: heroin; dependence; withdrawal; self-administration; choice; corticotropin-releasing factor I receptors

\section{INTRODUCTION}

Opioid addiction is thought to be motivated, at least in part, by the development of physical dependence and by negative reinforcing effects associated with the avoidance of drug withdrawal (Tatum et al, 1929; Koob and Le Moal, 2001). However, drug withdrawal in opioid-dependent organisms can produce a constellation of physiological and behavioral withdrawal signs (Seevers and Deneau, 1963; Blasig and Herz, 1977; O’Brien, 2006), and different withdrawal signs appear to be mediated by anatomically distinct receptor populations integrated into neural circuits that employ different neurotransmitters (Maldonado et al, 1992b; Koob

*Correspondence: Dr SS Negus, Department of Pharmacology and Toxicology, Virginia Commonwealth University, 410 North 12th Street, Richmond, VA 23298, USA, Tel: + I 804828 3158, Fax: + I 804828 2117, E-mail: ssnegus@vcu.edu

Received 3 June 2008; revised 19 July 2008; accepted 20 July 2008 and Le Moal, 2001; Frenois et al, 2002). For example, many somatic/autonomic signs of opioid withdrawal appear to be mediated by increased norepinephrine release from brain stem noradrenergic neurons (Gold et al, 1979; Aghajanian, 1982; Redmond and Huang, 1982). Conversely, some moodrelated and motivational signs of opioid withdrawal, such as conditioned place aversions and reductions in rates of foodmaintained responding, appear to be mediated by reductions in midbrain dopamine release in regions such as nucleus accumbens (Stinus et al, 1990; Acquas et al, 1991; Criner et al, 2007). The relative contribution of different withdrawal signs and their underlying mechanisms to addiction is a topic of continuing research.

Under appropriate conditions, opioid withdrawal can also increase the reinforcing efficacy of opioid agonists and increase rates of opioid self-administration. For example, withdrawal in opioid-dependent rats or rhesus monkeys increased rates of morphine-maintained responding under a chain schedule (Thompson and Schuster, 1964), break 
points maintained by morphine delivery under progressiveratio schedules (Yanagita, 1978; Carrera et al, 1999), and choice of morphine or heroin over food in choice procedures (Spragg, 1940; Griffiths et al, 1975; Negus, 2006). The degree to which mechanisms of withdrawalassociated increases in opioid self-administration overlap with mechanisms of other withdrawal signs remains to be established. However, drug self-administration procedures are useful for predicting determinants of drug-taking behavior in humans (Ator and Griffiths, 2003; Mello, 2005), and by extension, these procedures should be especially useful for investigating mechanisms that underlie the role of dependence and withdrawal in generating addictive patterns of drug use. Moreover, an improved understanding of these mechanisms may suggest new approaches to the treatment of opioid abuse and dependence.

Accordingly, the purpose of the present study was to use pharmacologic tools to examine mechanisms of withdrawalassociated increases in heroin self-administration in heroindependent rhesus monkeys. The $\mu$-opioid receptor agonist morphine was evaluated as a positive control, and we have shown previously that other $\mu$-agonists attenuated withdrawal-associated increases in heroin self-administration at doses that also decreased somatic withdrawal signs (Negus, 2006). The $\alpha-2$ noradrenergic agonist clonidine, dopamine/ norepinephrine releaser amphetamine, corticotropin-releasing factor 1 (CRF1) receptor antagonist antalarmin, and $\kappa$ opioid receptor antagonist $5^{\prime}$-guanidinonaltrindole (GNTI) were also tested to evaluate the role of non- $\mu$-opioid systems implicated in the expression of other opioid withdrawal signs. Clonidine reduces at least some somatic/autonomic withdrawal signs in rats, nonhuman primates, and humans (Tseng et al, 1975; Gold et al, 1979; Redmond and Huang, 1982; Jasinski et al, 1985; Katz, 1986; Sell et al, 2005). Clonidine also blocked acquisition of withdrawal-induced place aversions and attenuated withdrawal-induced disruption of operant responding in rats (Sparber and Meyer, 1978; Schaefer and Michael, 1983; Schulteis et al, 1998). These effects are generally thought to reflect an ability of $\alpha-2$ noradrenergic agonists to bind autoreceptors and suppress withdrawal-induced increases in norepinephrine release by brain stem noradrenergic neurons (Aghajanian, 1982; Delfs et al, 2000; Van Bockstaele et al, 2008). However, clonidine did not alter other withdrawal signs, including the discriminative stimulus effects of withdrawal in rats or rhesus monkeys (Gellert and Holtzman, 1979; France and Woods, 1989) or the subjective effects of withdrawal in humans (Jasinski et al, 1985; Walsh et al, 2003). In contrast to clonidine, amphetamine decreased the discriminative stimulus effects of opioid withdrawal but did not attenuate somatic withdrawal signs in rhesus monkeys (Sell and France, 2002; McMahon et al, 2004; Sell et al, 2005). The selective effect of amphetamine on the discriminative stimulus effects of opioid withdrawal was interpreted to suggest an ability of amphetamine to attenuate withdrawalinduced suppression of mesolimbic dopamine levels (Sell and France, 2002).

Endogenous CRF and dynorphin/ $\kappa$-opioid receptor systems are also activated during chronic exposure to opioids and other abused drugs, and it has been suggested that activity of these neurotransmitter systems opposes the positive-reinforcing effects of abused drugs and contributes to aversive, dysphoric, and/or anxiogenic effects of withdrawal (Koob and Le Moal, 2001; Koob et al, 2004; Walker and Koob, 2008). In support of this proposition, CRF antagonists including antalarmin blocked some somatic withdrawal signs (Brugger et al, 1998; Iredale et al, 2000; Lu et al, 2000; Skelton et $a l, 2007)$ as well as withdrawalinduced place aversions in rats (Heinrichs et al, 1995; Stinus et $a l, 2005) . \kappa$-Receptors appear to play only a minor role in expression of somatic withdrawal signs in rats (Maldonado et al, 1992a), and the effects of $\kappa$-antagonists on motivational and mood-related aspects of opioid withdrawal have not been evaluated. However, the $\kappa$-antagonist norbinaltorphimine did decrease escalated ethanol self-administration in ethanol-dependent rats (Walker and Koob, 2008).

In the present study, drug effects were evaluated in an assay of heroin $v s$ food choice in heroin-dependent rhesus monkeys undergoing withdrawal. This choice procedure was used for two reasons. First, we and others have shown previously that either spontaneous or precipitated opioid withdrawal dramatically increases choice of morphine or heroin over food (Spragg, 1940; Griffiths et al, 1975; Negus, 2006; Negus, in press). Consequently, choice procedures have demonstrated sensitivity for detection of withdrawal-associated increases in the relative reinforcing efficacy of $\mu$-agonists. Second, choice studies provide a rate-independent measure of reinforcing efficacy (percent heroin choice), and as a result, effects of withdrawal or pharmacologic manipulations on choice can be dissociated from effects on response rates (Griffiths et al, 1975; Negus, 2003).

\section{METHODS}

\section{Animals}

Studies were conducted in five adult male rhesus monkeys (Macaca mulatta) that had been surgically implanted with double-lumen catheters using aseptic procedures as described previously (Negus and Mello, 2004). Monkeys weighed $6-10 \mathrm{~kg}$ and were maintained on a diet of multiple vitamins, fresh fruit, and food biscuits (Lab Diet Jumbo Monkey Biscuits, PMI Feeds Inc., St Louis, MO). In addition, monkeys received up to $501 \mathrm{~g}$ banana flavored pellets (Precision Primate Pellets Formula L/I Banana Flavor, PJ Noyes Co., Lancaster, NH) during daily operant sessions. Water was continuously available. A $12 \mathrm{~h}$ lightdark cycle was in effect (lights on from 0700 to 1900 hours).

Animal maintenance and research were conducted in accordance with the guidelines provided by the NIH Committee on Laboratory Animal Resources. The facility was licensed by the United States Department of Agriculture, and protocols were approved by the Institutional Animal Care and Use Committee.

\section{Apparatus and Catheter Maintenance}

Experimental sessions were conducted in each monkey's home cage. The front wall was equipped with an operant response panel $\left(28 \times 28 \mathrm{~cm}^{2}\right)$ that included three circular response keys $(5.1 \mathrm{~cm}$ in diameter) arranged $2.5 \mathrm{~cm}$ apart horizontally. Each key could be illuminated by red or yellow 
stimulus lights. Each housing chamber was also equipped with a pellet dispenser (Gerbrands, Model G5210, Arlington, MA) and two syringe pumps (Model PHM-100, Med Associates Inc., St Albans, VT). One syringe pump was used to deliver self-administered heroin injections through one lumen of the double-lumen catheter. The second syringe pump (the 'treatment' pump) was used to deliver saline or treatment drugs through the second lumen of the catheter. This second pump was programmed to deliver $0.1 \mathrm{ml}$ infusions every $20 \mathrm{~min}$ from 1000 hours each day until 0900 hours the next morning. Operation of the operant response panels and data collection were accomplished with microprocessors and software purchased from Med Associates Inc. (St Albans, VT). The catheter was protected by a custom-fitted nylon vest connected to a flexible stainless steel cable and fluid swivel (Lomir Biomedical, Malone, NY).

\section{Behavioral Procedures}

Training procedures. Behavioral sessions were conducted 7 days a week as described previously (Negus, 2006). Choice sessions were conducted during daily $2 \mathrm{~h}$ sessions from 1100 to 1300 hours. The terminal choice schedule consisted of five 20 -min response periods separated by $5 \mathrm{~min}$ timeout periods (total session duration of $120 \mathrm{~min}$ ). During each response period, the left, food-associated key was illuminated with red stimulus lights, and completion of the fixedratio (FR) requirement resulted in the delivery of a food pellet. The right, heroin-associated key was illuminated with yellow stimulus lights, and completion of the FR requirement on this key resulted in the delivery of a heroin dose. A different heroin dose was available during each of the five successive response periods $(0,0.0032,0.01,0.032$, and $0.1 \mathrm{mg} / \mathrm{kg}$ per injection during response periods $1-5$, respectively), and dose was varied by varying the duration of pump activation and the resulting volume of each injection. Stimulus conditions on the drug-associated key were also varied by flashing the stimulus lights on and off in $3 \mathrm{~s}$ cycles (response period 1: $0 \mathrm{~s}$ on, $3 \mathrm{~s}$ off; response period 2: $0.1 \mathrm{~s}$ on, $2.9 \mathrm{~s}$ off; response period $3: 0.3 \mathrm{~s}$ on, $2.7 \mathrm{~s}$ off; response period 4: $1 \mathrm{~s}$ on, $2 \mathrm{~s}$ off; and response period 5: $3 \mathrm{~s}$ on, $0 \mathrm{~s}$ off). The response requirements were set at FR 100 on the food-associated key and FR 10 on the heroinassociated key for all monkeys, because our previous studies indicated that under these response requirements, monkeys usually switched from the food-associated key to the drug-associated key during the fourth response period, when an intermediate unit dose of $0.032 \mathrm{mg} / \mathrm{kg}$ per injection heroin was available (Negus, 2005; Negus, 2006). Consequently, these parameters permitted detection of both leftward and rightward shifts in heroin choice dose-effect curves.

During each response period, monkeys could complete up to 10 total ratio requirements on the food- and heroinassociated keys. Responding on either key reset the ratio requirement on the other key. Completion of each ratio requirement initiated a $30 \mathrm{~s}$ time-out, during which all stimulus lights were turned off, and responding had no scheduled consequences. If all 10 ratio requirements were completed before the $20 \mathrm{~min}$ response period had elapsed, then all stimulus lights were extinguished and responding had no scheduled consequences for the remainder of that 20 -min response period. Choice training was considered to be complete when the lowest heroin dose maintaining at least $80 \%$ heroin choice varied by $\leqslant 0.5 \log$ units for three consecutive days.

Once responding under the choice schedule was stable, an additional daily 'supplemental session' of heroin availability was introduced as described previously to permit increased heroin intake and the development of physical dependence (Negus, 2006). Daily supplemental sessions began at 1300 hours (ie immediately after the choice session) and concluded the next morning at 1000 hours. During this 21-h supplemental session, the heroin-associated key was illuminated with yellow lights, and heroin $(0.1 \mathrm{mg} / \mathrm{kg}$ per injection) was available under an FR 10 schedule. To limit heroin intake and prevent overdose toxicity, a time-out of $60 \mathrm{~min}$ was initially implemented after each heroin delivery, and this time-out was gradually reduced to $15 \mathrm{~min}$. Training was considered to be complete once monkeys had access to supplemental heroin under the terminal FR10/time-out 15 min schedule for at least 3 weeks, and heroin $v s$ food choice during the daily choice sessions stabilized as defined by the criteria listed above.

Testing procedures. Each test session was preceded by a 22-h period of heroin withdrawal, which was achieved by omitting one supplemental heroin self-administration session. During this period of heroin withdrawal, monkeys received noncontingent treatment with saline, morphine (0.032-0.32 mg/kg/h), clonidine (0.01-0.1 mg/kg/h), amphetamine $(0.032-0.1 \mathrm{mg} / \mathrm{kg} / \mathrm{h})$, antalarmin $(1-10 \mathrm{mg} / \mathrm{kg}$ per day), or $5^{\prime}$-guanidinonaltrindole (GNTI; $1.0 \mathrm{mg} / \mathrm{kg}$ ). Test drugs and doses were presented in a mixed order across monkeys, and testing with any one drug was completed before testing with another drug was initiated. Each drug was tested in a group of three or four monkeys, and all monkeys did not receive all test drugs. Saline, morphine, clonidine, and amphetamine were delivered i.v. by automated infusions from the 'treatment pump' at a rate of $0.1 \mathrm{ml}$ every $20 \mathrm{~min}$. A syringe containing the treatment solution was inserted into the 'treatment pump' at 1300 hours on the preceding day, immediately after the preceding choice session, and it remained in place for $24 \mathrm{~h}$ until the conclusion of the test session. Because of the viscosity of its vehicle, antalarmin was delivered by i.m. injection at 1400 and 1000 hours before the test session. Because of its long duration of action, GNTI was administered as a single i.m. injection at 1400 hours on the day before the test session. Doses and treatment intervals were based on previous studies with these drugs in rhesus monkeys (Katz, 1986; Negus and Mello, 2002; Negus et al, 2002; Negus, 2003; Broadbear et al, 2004; Mello et al, 2006). At the conclusion of each test session, access to supplemental heroin selfadministrations was reinstated for at least 3 days and until heroin and food choice recovered to baseline levels. Delivery of test drugs was suspended for at least 3 weeks after GNTI treatment to allow the long-acting $\kappa$-antagonist effects of GNTI to dissipate.

During each period of heroin withdrawal, monkeys were also observed for overt signs of opioid withdrawal at 1400, 1700, and 1030 hours. As described previously (Negus, 
2006), eight withdrawal signs were counted as present or absent during each withdrawal assessment, and the total number of withdrawal signs were counted to yield a withdrawal score (ie maximum withdrawal score was ' 8 '). The eight signs were lying on bottom of cage, unusually aggressive or lethargic response to investigator, increased vocalization, retching/emesis, diarrhea, penile erection/ masturbation, tremor/convulsion, and a category for other unusual behaviors.

\section{Data Analysis}

The primary dependent variables for each response period were: (1) \% Heroin choice, defined as ((number response requirements completed on the heroin-associated key/total number of response requirements completed) $\times 100$ ), and (2) total number of response requirements completed (referred to hereafter as 'number of choices'). These variables were then plotted as a function of heroin dose. In addition to these data for each response period, total session data were also calculated for percent heroin choice, number of choices, withdrawal score, number of food choices, number of heroin choices, and total heroin intake. Mean data from supplemental sessions and choice sessions immediately preceding test sessions were averaged to yield baseline measures of supplemental heroin self-administration and heroin $v s$ food choice. Statistical analyses were performed to assess effects of heroin withdrawal and of treatment with the test drugs on (1) percent heroin choice for the entire session, (2) number of total choices, food choices, heroin choices, and heroin intake for the entire session, and (3) withdrawal score during the 1030 hours assessment, just before the choice session started. Statistical analyses were accomplished by $t$-tests or one-way ANOVA as appropriate with withdrawal state or test-drug dose as the independent variable (GraphPad Software, San Diego, CA). A significant ANOVA was followed by the Dunnett's post hoc test. The criterion for significance was set at $p<0.05$.

\section{Drugs}

Heroin $\mathrm{HCl}$ and morphine sulfate (provided by the National Institute on Drug Abuse Drug Supply Program, Bethesda, $\mathrm{MD})$, and clonidine $\mathrm{HCl}, d$-amphetamine sulfate, and $5^{\prime}$ GNTI bis(trifluoroacetate) (Sigma Chemical Co., St Louis, MO) were dissolved in sterile water. Antalarmin (supplied by Dr Kenner C Rice, NIDA/NIAAA, NIH) was dissolved in a vehicle of $10 \%$ ethanol, $10 \%$ emulphor, and $1 \%$ lactic acid in sterile water. Heroin, morphine, clonidine, and amphetamine were delivered i.v., whereas antalarmin and GNTI were delivered i.m. All drug doses are expressed in terms of the salts named above.

\section{RESULTS}

\section{Baseline Choice Between Heroin and Food}

Under baseline conditions, when monkeys had access to heroin during both supplemental heroin self-administration sessions and choice sessions, monkeys self-administered an average $\pm S E M$ of $4.69 \pm 0.45 \mathrm{mg} / \mathrm{kg}$ per day heroin $(3.66 \pm 0.35 \mathrm{mg} / \mathrm{kg}$ during supplemental sessions and
Table I Mean \pm SEM Number of $0.1 \mathrm{mg} / \mathrm{kg}$ Per Injection Heroin Injections Delivered During Each Quintile of Supplemental Heroin Self-Administration Sessions

Quintile of session Number injections

Quintile I (1300-17/2h)

$10.63 \pm 0.78$

Quintile 2 ( $17 / 2-2124 \mathrm{~h})$

$6.72 \pm 1.28$

Quintile 3 (2124-0136h)

$3.70 \pm 1.04$

Quintile 4 (0136-0548 h)

$4.69 \pm 0.80$

Quintile 5 (0548-1000 h)

$10.86 \pm 0.39$

The time corresponding to each quintile is indicated in parentheses.

$1.03 \pm 0.12 \mathrm{mg} / \mathrm{kg}$ during choice sessions). Self-administration during supplemental sessions was highest during the afternoon and early morning, and lowest at night (Table 1). Figure 1 (closed bars and symbols) shows mean data from baseline heroin choice sessions for all five monkeys used in the study. Figure 1a shows the mean percent heroin choice for the entire choice session. On average, monkeys allocated approximately $40 \%$ of their choices to heroin, with the remaining choices being allocated to food. Figure $1 \mathrm{~b}$ shows percent heroin choice during each component of the choice session. Heroin maintained a dose-dependent and monotonic increase in heroin choice. When low unit dose of heroin were available $(0-0.01 \mathrm{mg} / \mathrm{kg}$ injection), monkeys responded primarily for food, and percent heroin choice was low. When higher unit doses of heroin were available (0.032-0.1 mg/kg per injection), monkeys responded primarily for heroin, and percent heroin choice was high.

Figures 1c and d show the total number of choices completed during the entire session and during each component, respectively. Out of a maximum possible 50 choices during each session, monkeys completed the response requirement for more than 40 choices, and the number of choices was evenly distributed across the session (approximately eight choices during each component). Table 2 shows the mean numbers of food choices and heroin choices completed during each session, and the mean heroin intake during choice sessions. As noted above, most choices were allocated to food, and heroin intake during choice sessions averaged just over $1 \mathrm{mg} / \mathrm{kg}$.

Figure le shows the baseline withdrawal score. Monkeys did not show any withdrawal signs during access to supplemental heroin self-administration sessions.

\section{Effects of Heroin Withdrawal}

Figure 1 (open bars and symbols) and Table 2 also show the effects of heroin withdrawal, which was produced by omitting one supplemental heroin self-administration session. Significant statistical results are reported in the figure and table legends. Heroin withdrawal significantly increased percent heroin choice for the entire session (Figure 1a), and produced a leftward-upward shift in the heroin choice dose-effect curve (Figure 1b). Withdrawal also significantly decreased the total number of choices per session (Figure 1c). This decrease in total choices was largely a result of a decrease in the number of choices during the first component of the choice session (Figure 1d), when the heroin-associated key was not illuminated and no heroin 
a

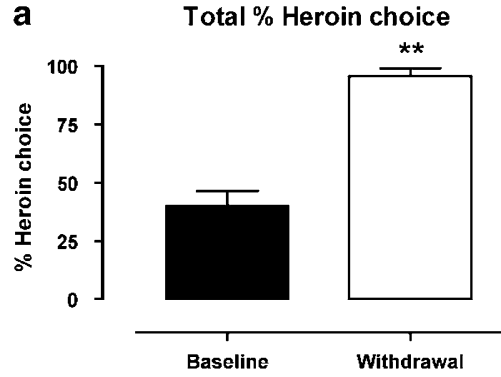

b

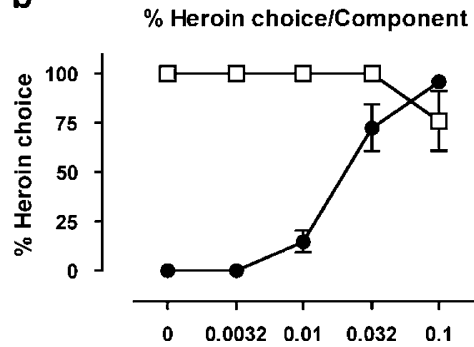

c

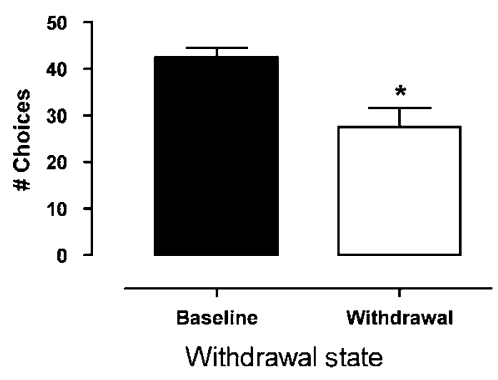

d

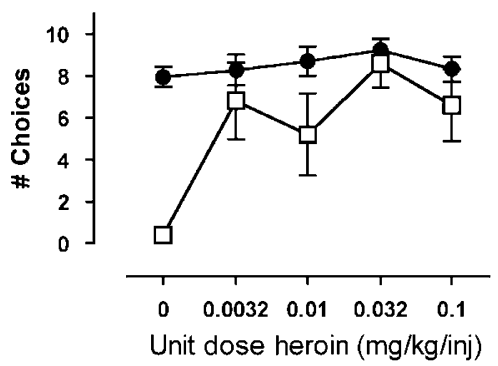

Unit dose heroin $(\mathrm{mg} / \mathrm{kg} / \mathrm{inj})$ e

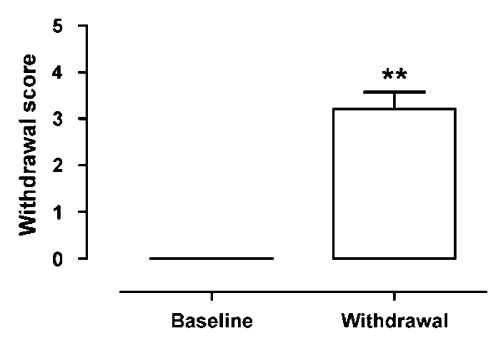

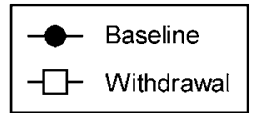

Figure I Effects of heroin withdrawal on percent heroin choice, number of choices completed and withdrawal scores. (a, b) Percent heroin choice for the entire session and for each component of the choice session, respectively (maximum $=100 \%$ heroin choice for total session and for each component). (c, $d$ ) Total number of choices for the entire session and for each component of the session, respectively (maximum $=50$ for the entire session and 10 for each component of the session). (e) The withdrawal score (maximum score =8). Closed bars and symbols show data for baseline sessions, which were defined as sessions immediately preceding test sessions. Open bars and symbols show data obtained after $22 \mathrm{~h}$ of heroin withdrawal, which was produced by omitting one supplemental session of heroin self-administration. Abscissae (top panels): withdrawal state of the subjects. Abscissae (bottom panels): unit dose heroin in $\mathrm{mg} / \mathrm{kg}$ per injection available during each sequential component of the choice session. All figures show mean data for five monkeys, and error bars indicate SEM. Data in (a), (c), and (e) were evaluated with $t$-tests to compare baseline and withdrawal data. There was a significant effect of withdrawal on total percent heroin choices $(t(4)=7.00, p=0.002)$, total number of choices $(t(4)=3.20 ; p=0.033)$, and withdrawal score $(t(4)=8.55 ; p=0.00 \mathrm{I})$. Asterisks in panels (a), (c) and (e) indicate significant differences from baseline; ${ }^{*} p<0.05$ and ${ }^{*} * 0.0$ l.

was available. However, two of the five monkeys completed the response requirement for one choice each during this component, and both monkeys responded exclusively on the heroin-associated key. It should also be noted that the decrease in the number of total choices was due exclusively to a decrease in the number of food choices, whereas the number of heroin choices increased (Table 2). The increase in the number of heroin choices did not produce an increase in heroin intake, because increased heroin choice was observed at relatively low unit doses of heroin that contributed little to overall intake.

Heroin withdrawal also significantly increased the withdrawal score measured just before the start of the choice session (Figure 1e). The most commonly observed signs were 'lying on bottom of cage,' 'lethargic response to investigator,' and 'increased vocalization.'

\section{Effects of Morphine Treatment During Heroin Withdrawal}

Figure 2 shows the effects of morphine on percent heroin choice, number of choices, and withdrawal scores during heroin withdrawal. Relative to untreated heroin withdrawal, morphine dose-dependently and significantly decreased heroin choice (Figure 2a), and produced downward-rightward shifts in the heroin choice dose-effect curve (Figure 2b). Heroin choice during treatment with the highest dose of $0.32 \mathrm{mg} / \mathrm{kg} / \mathrm{h}$ morphine was similar to baseline heroin choice. Morphine also tended to increase the total number of choices completed for the entire session (Figure 2c, $p=0.07$ ), and this effect was most apparent during the first component, when the number of choices was most suppressed by untreated withdrawal (Figure 2d). Table 2 shows that morphine significantly increased the number of food choices per session, although tending to decrease the number of heroin choice per session. Heroin intake was not affected by morphine treatment. Finally, morphine dose-dependently and significantly prevented the emergence of withdrawal signs (Figure 2e).

\section{Effects of Clonidine Treatment During Heroin Withdrawal}

Figure 3 shows the effects of treatment with the $\alpha-2$ noradrenergic agonist clonidine. Clonidine had little or no effect on withdrawal-associated increases in heroin choice (Figure $3 \mathrm{a}$ and $\mathrm{b}$ ). Clonidine treatment tended to decrease the number of choices below the values observed during withdrawal, but this effect was not dose-dependent and did not achieve statistical significance (Figure $3 \mathrm{c}$ and d; Table 2). One monkey did not respond at all during treatment with 0.01 or $0.1 \mathrm{mg} / \mathrm{kg} / \mathrm{h}$ clonidine, and this monkey was not tested with the intermediate dose of $0.032 \mathrm{mg} / \mathrm{kg} / \mathrm{h}$. Clonidine treatment produced modest decreases in withdrawal scores, but these decreases were not dose-dependent or statistically significant (Figure $3 \mathrm{e}$ ). During these withdrawal observations, monkeys appeared relatively inactive and unresponsive to external stimuli, but the scoring system 
Table 2 Mean \pm SEM Number Food Choices/Session, Heroin Choices/Session, and Heroin Intake Under Various Treatment Conditions

\begin{tabular}{lcll}
\hline Treatment condition & $\begin{array}{c}\text { Food } \\
\text { choices }\end{array}$ & $\begin{array}{l}\text { Heroin } \\
\text { choices }\end{array}$ & $\begin{array}{l}\text { Heroin } \\
\text { intake }\end{array}$ \\
\hline Baseline & $26.5 \pm 2.9$ & $16.0 \pm 2.3$ & $1.03 \pm 0.12$ \\
Heroin withdrawal & $1.6 \pm 1.4^{* *}$ & $26.0 \pm 2.9 *$ & $0.85 \pm 0.17$
\end{tabular}

$\begin{array}{lccc}\begin{array}{l}\text { Morphine+heroin withdrawal } \\ \text { Saline }\end{array} & 2.0 \pm 1.7 & 26.0 \pm 3.8 & 0.72 \pm 0.14 \\ 0.032 / h & 3.0 \pm 2.7 & 23.8 \pm 5.9 & 1.07 \pm 0.15 \\ 0.1 / h & 18.0 \pm 6.3^{\dagger} & 20.5 \pm 4.7 & 0.94 \pm 0.21 \\ 0.32 / h & 33.8 \pm 2.4^{\dagger \dagger} & 14.0 \pm 2.0 & 0.97 \pm 0.07\end{array}$

Clonidine+heroin withdrawal

$\begin{array}{lcrl}\text { Saline } & 2.7 \pm 2.2 & 28.0 \pm 4.5 & 0.59 \pm 0.1 \\ 0.0 \mathrm{I} / \mathrm{h} & 0.3 \pm 0.3 & 14.3 \pm 7.3 & 0.43 \pm 0.22 \\ 0.032 / \mathrm{h}(\mathrm{N}=2) & 0 \pm 0 & 25 \pm 16 & 0.44 \pm 0.11 \\ 0.1 / \mathrm{h} & 0.3 \pm 0.3 & 16.3 \pm 8.4 & 0.71 \pm 0.40\end{array}$

Amphetamine+heroin withdrawal

$\begin{array}{lccc}\text { Saline } & 2.7 \pm 2.2 & 30.3 \pm 2.2 & 0.89 \pm 0.24 \\ 0.032 / h & 0 \pm 0 & 16.3 \pm \mid 4.7 & 0.45 \pm 0.31 \\ 0.1 / h & 9.3 \pm 9.3 & 7.3 \pm 7.3 & 0.18 \pm 0.18\end{array}$

$\begin{array}{llll}\text { Antalarmin+heroin withdrawal } & & & \\ \text { Saline } & 2.7 \pm 2.2 & 28.3 \pm 4.2 & 0.81 \pm 0.2 \\ \text { 1.0 per day } & 3.2 \pm 3.3 & 28.0 \pm 6.6 & 0.95 \pm 0.30 \\ 3.2 \text { per day } & 6.0 \pm 4.6 & 22.0 \pm 2.9 & 0.76 \pm 0.10 \\ \text { I0 per day } & 9.3 \pm 7.9 & 20.3 \pm 10.1 & 0.66 \pm 0.28\end{array}$

$\begin{array}{lcrl}\text { GNTI+heroin withdrawal } & & & \\ \text { Saline } & 2.7 \pm 2.2 & 28.3 \pm 4.2 & 0.81 \pm 0.2 \\ 1.0 & 0 \pm 0 & 12 \pm 4.9 & 0.63 \pm 0.32\end{array}$

$t$-Tests were used to compare data obtained during 'baseline' and 'heroin withdrawal'.

Significant effects of withdrawal were obtained only for food choices $(t(4)=6.88, p=0.002)$ and heroin choices $(t(4)=3.32, p=0.029)$, and asterisks $(*)$ indicate a significant difference of 'heroin withdrawal' from 'baseline' $(* p<0.05$; $* * 2<0.0$ I). t-Tests (GNTI) or ANOVAs (other drugs) were used to compare data obtained during treatment with saline and each dose of each test drug during withdrawal. The only significant ANOVA was obtained for food choices during treatment with morphine $(F(3,9)=16.9, p<0.001)$. Daggers $(\dagger)$ indicate significant difference between food choices during treatment with saline and different morphine doses as determined by the Dunnett post hoc test $\left({ }^{\dagger} p<0.05 ;{ }^{\dagger} p<0.01\right)$.

did not permit a straightforward distinction between potential decreases in activity and responsiveness produced by sedative effects of clonidine $v s$ withdrawal.

\section{Effects of Amphetamine Treatment During Heroin Withdrawal}

Figure 4 shows the effects of treatment with the dopamine/ norepinephrine releaser amphetamine. The lowest dose of $0.032 \mathrm{mg} / \mathrm{kg} / \mathrm{h}$ amphetamine had no significant effect on any of the dependent measures. During treatment with the highest dose of $0.1 \mathrm{mg} / \mathrm{kg} / \mathrm{h}$ amphetamine, only one monkey responded, and the percent heroin choice for the entire session was reduced in this monkey (Figure 4a). However, this reduction in percent heroin choice resulted from an erratic allocation of choice that was not related to heroin dose (Figure 4b). For example, percent heroin choice was highest during the first component when no heroin was available. Two other monkeys did not respond at all during treatment with the highest dose of $0.1 \mathrm{mg} / \mathrm{kg} / \mathrm{h}$ amphetamine, and overall, amphetamine treatment tended to reduce the number of choices completed (Figure 4c and d; Table 2). Amphetamine treatment also had little effect on withdrawal scores (Figure 4e).

One monkey died approximately $18-20 \mathrm{~h}$ after termination of treatment with the highest dose of $0.1 \mathrm{mg} / \mathrm{kg} / \mathrm{h}$ amphetamine. The cause of death was not readily apparent, and it was not clear if amphetamine treatment played a contributing role (ie this monkey responded during all five quintiles of the supplemental heroin self-administration that began immediately after the test session). However, a role for the amphetamine treatment cannot be excluded.

\section{Effects of Antalarmin Treatment During Heroin Withdrawal}

Figure 5 and Table 2 show the effects of treatment with the CRF1 receptor antagonist antalarmin. In the analysis of the mean data for the three monkeys tested, antalarmin did not significantly alter percent heroin choice, total choices, or the withdrawal score. However, in one monkey (monkey RQ2393), antalarmin produced a morphine-like reduction in heroin choice and withdrawal score and an increase in total choices (Figure 6). These effects were dose dependent, and the effects of the highest dose of $10 \mathrm{mg} / \mathrm{kg}$ antalarmin were replicated in a subsequent test (data not shown). Monkey RQ2393 was also the only monkey to respond during treatment with the highest dose of $0.1 \mathrm{mg} / \mathrm{kg} / \mathrm{h}$ amphetamine, but this monkey did not show a notably different response to withdrawal or to treatments with the other test drugs.

\section{Effects of GNTI Treatment During Heroin Withdrawal}

Figure 7 and Table 2 show the effects of treatment with the $\kappa$-receptor antagonist GNTI. Relative to untreated withdrawal, GNTI did not significantly alter percent heroin choice, total choices, or the withdrawal score, although there was a tendency for GNTI to decrease the number of choices completed.

\section{DISCUSSION}

Drug withdrawal in opioid-dependent organisms can produce a robust increase in the relative reinforcing efficacy of opioid agonists in comparison to alternative reinforcers. We have argued previously that this withdrawal-induced enhancement in the relative reinforcing efficacy of opioid agonists may contribute to addiction and relapse by channeling behavior toward drug use and away from activities maintained by alternative reinforcers (Negus, 2006). The present study used pharmacologic tools to 
a

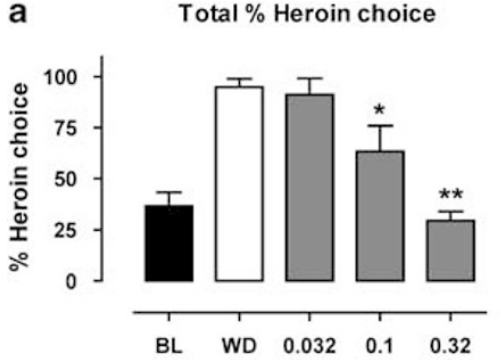

b

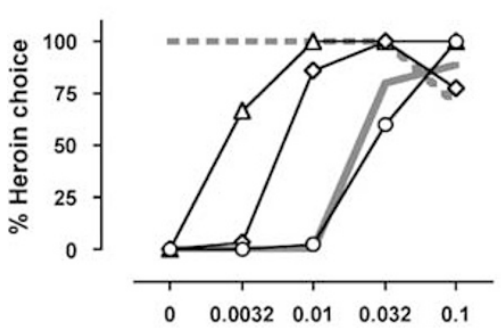

c

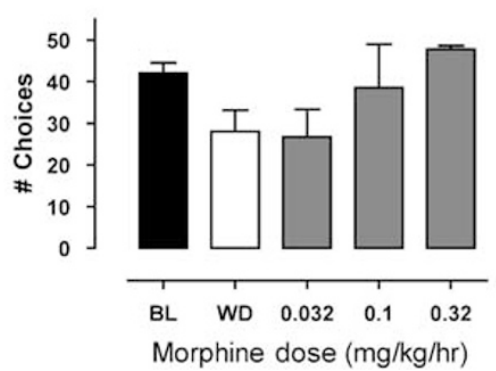

e

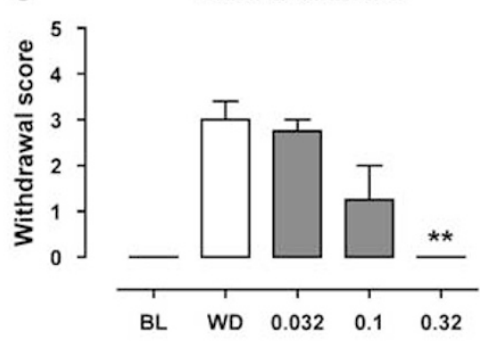

d

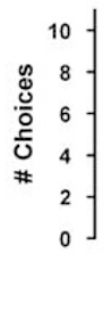

\# Choices/Component

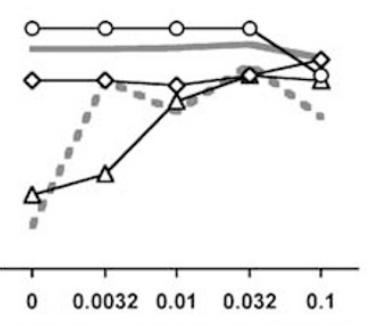

Unit dose heroin (mg/kg/inj)

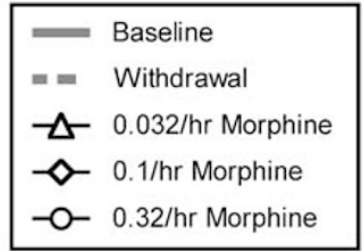

Figure 2 Effects of morphine treatment (0.032-0.32 mg/kg/h) during heroin withdrawal. (a, b) Percent heroin choice for the entire session and for each component of the choice session, respectively (maximum $=100 \%$ heroin choice for total session and for each component). (c, d) Total number of choices for the entire session and for each component of the session, respectively (maximum $=50$ for the entire session and 10 for each component of the session).

(e) The withdrawal score (maximum score = 8). Abscissae (top panels): dose morphine in mg/kg/h. Closed bars above 'BL' and open bars above 'WD' show data from baseline and heroin withdrawal sessions, respectively. Abscissae (bottom panels): unit dose heroin in mg/kg per injection available during each component of the choice session. All figures show mean data from four monkeys, and error bars indicate SEM. ANOVA was used to compare data for each drug dose with 'WD' in (a), (c), and (e), and there was a significant effect of morphine dose on total percent heroin choice $(F(3,9)=15.87, p<0.00 \mathrm{I})$ and withdrawal score $(F(3,9)=10.07, p=0.003)$, and the effect on total number of choices approached significance $(F(3,9)=3.07, p=0.07)$. Asterisks in $(a)$ and (e) indicate morphine doses producing effects significantly different from 'WD' as determined by a Dunnett's post hoc test; * $p<0.05$ and $* * p<0.0$ I.

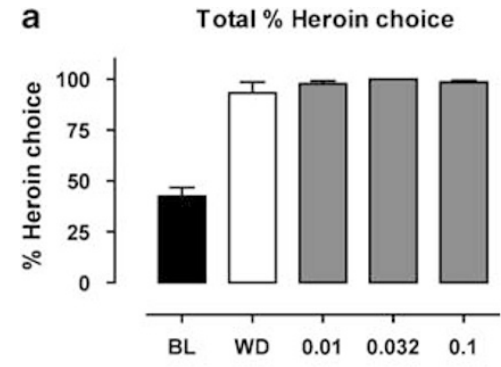

b

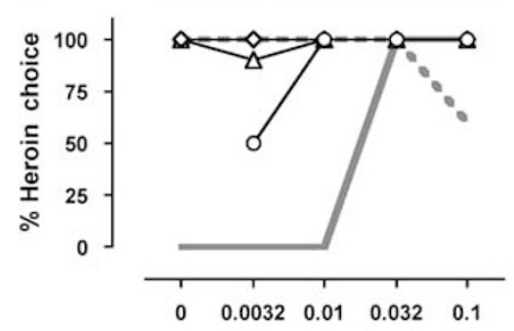

C

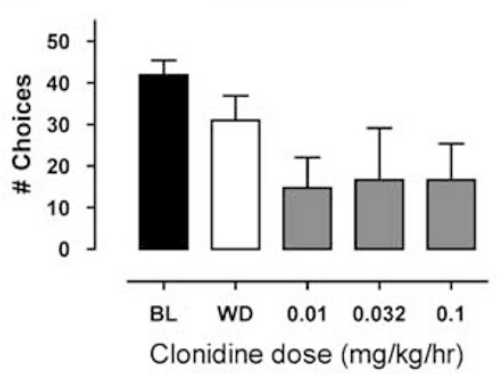

d

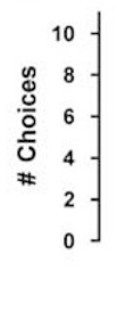

\# Choices/Component
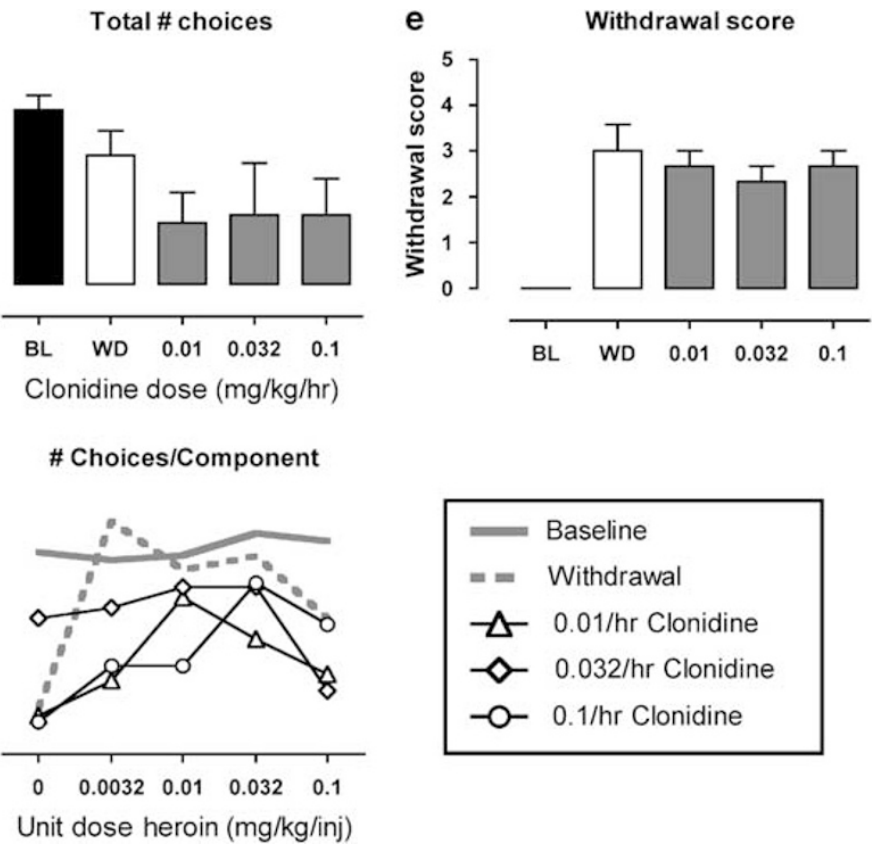

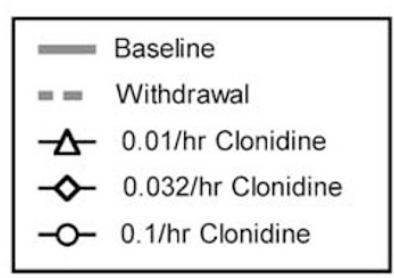

Unit dose heroin $(\mathrm{mg} / \mathrm{kg} / \mathrm{inj})$

Figure 3 Effects of clonidine treatment $(0.01-0.1 \mathrm{mg} / \mathrm{kg} / \mathrm{h}$ ) during heroin withdrawal. Abscissae (top panels): dose clonidine in mg/kg/h. All panels show mean data in three monkeys, except that effects of $0.032 \mathrm{mg} / \mathrm{kg} / \mathrm{h}$ clonidine were examined in only two monkeys. ANOVA was used to compare data for each drug dose with 'WD' in (a), (c), and (e), and there was not a significant effect of clonidine dose on any measure ( $p>0.05)$. All other details as in Figure 2.

evaluate potential mechanisms of withdrawal-associated increases in heroin choice by heroin-dependent rhesus monkeys. The main finding was that only the $\mu$-opioid agonist morphine prevented withdrawal-associated increases in heroin choice in all monkeys. Conversely, drugs acting at other, non- $\mu$-opioid targets reputedly involved in 

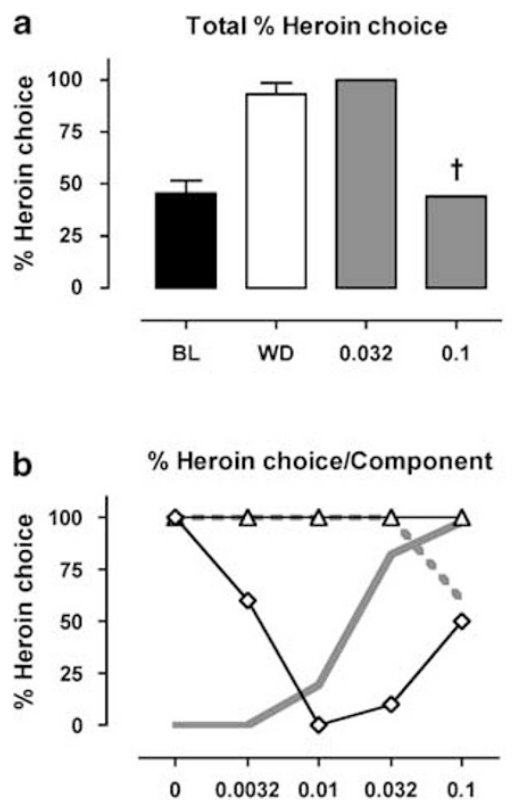

C

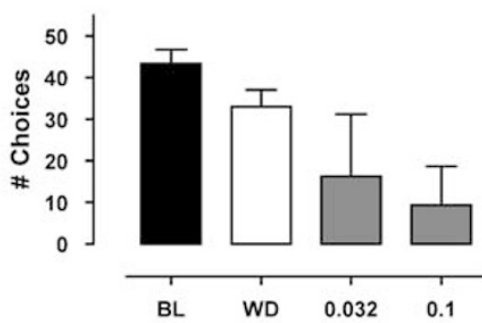

Amphetamine dose $(\mathrm{mg} / \mathrm{kg} / \mathrm{hr})$

d

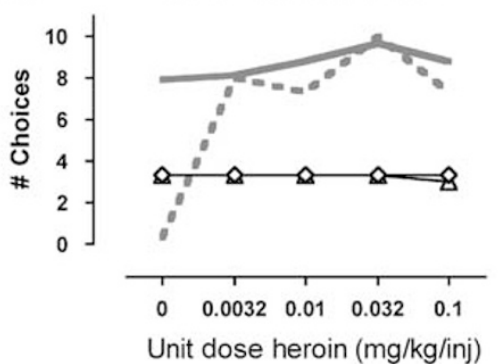

Unit dose heroin $(\mathrm{mg} / \mathrm{kg} / \mathrm{inj})$ e Withdrawal score

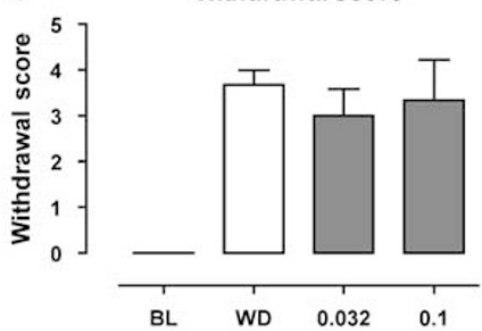

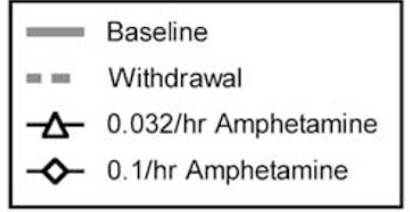

Figure 4 Effects of amphetamine treatment $(0.032-0.1 \mathrm{mg} / \mathrm{kg} / \mathrm{h})$ during heroin withdrawal. Abscissae (top panels): dose amphetamine in mg/kg/h. All panels show mean data in three monkeys. ANOVA was used to compare data for each drug dose with 'WD' in (a), (c), and (e), and there was not a significant effect of amphetamine dose on any measure $(p>0.05)$. Dagger $(\dagger)$ indicates that only one monkey responded during treatment with the highest amphetamine dose, and percent heroin choice could be determined only in this one monkey. All other details as in Figure 2.

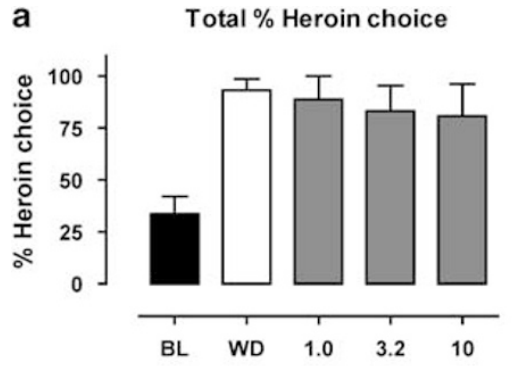

b

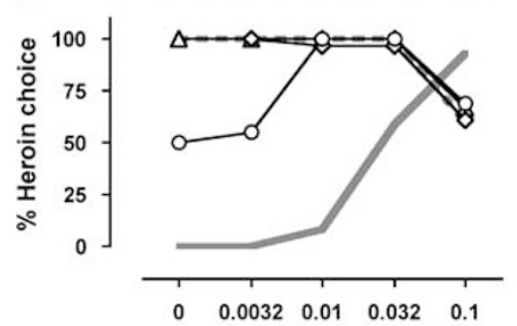

c

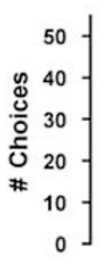

d

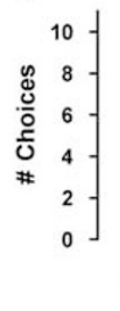

Total \# Choices

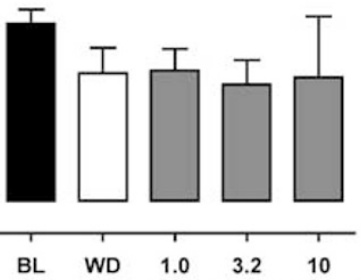

Antalarmin dose $(\mathrm{mg} / \mathrm{kg} / \mathrm{day})$

\# Choices/Component

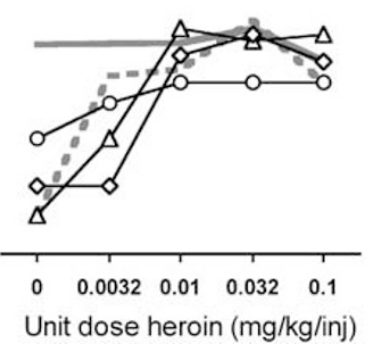

Unit dose heroin $(\mathrm{mg} / \mathrm{kg} / \mathrm{inj})$ e Withdrawal score
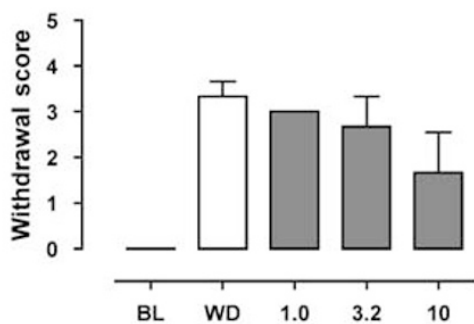

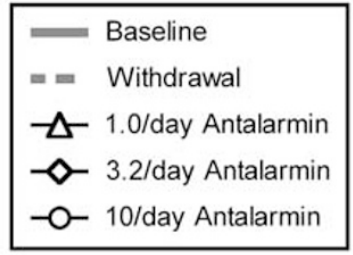

Figure 5 Effects of antalarmin treatment ( $1.0-10 \mathrm{mg} / \mathrm{kg}$ per day) during heroin withdrawal. Abscissae (top panels): dose antalarmin in $\mathrm{mg} / \mathrm{kg}$ per day. ANOVA was used to compare data for each drug dose with 'WD' in (a), (c), and (e), and there was not a significant effect of antalarmin dose on any measure $(p>0.05)$. All panels show mean data in three monkeys. All other details as in Figure 2.

expression of other withdrawal signs did not reliably affect withdrawal-associated increases in heroin choice. These findings suggest that withdrawal-associated increases in opioid reinforcement may be mediated by mechanisms different from or more extensive than those that mediate other somatic, mood-related, and motivational withdrawal signs. A corollary to this general conclusion is that assessment of medication effects on other withdrawal signs may not be predictive of effects on withdrawal-associated increases in opioid reinforcement. Insofar as drug selfadministration procedures are especially useful for predicting determinants of drug-taking behavior by humans, these findings further suggest that evaluation of withdrawal mechanisms contributing to opioid addiction should include studies that examine withdrawal effects on opioid self-administration. 

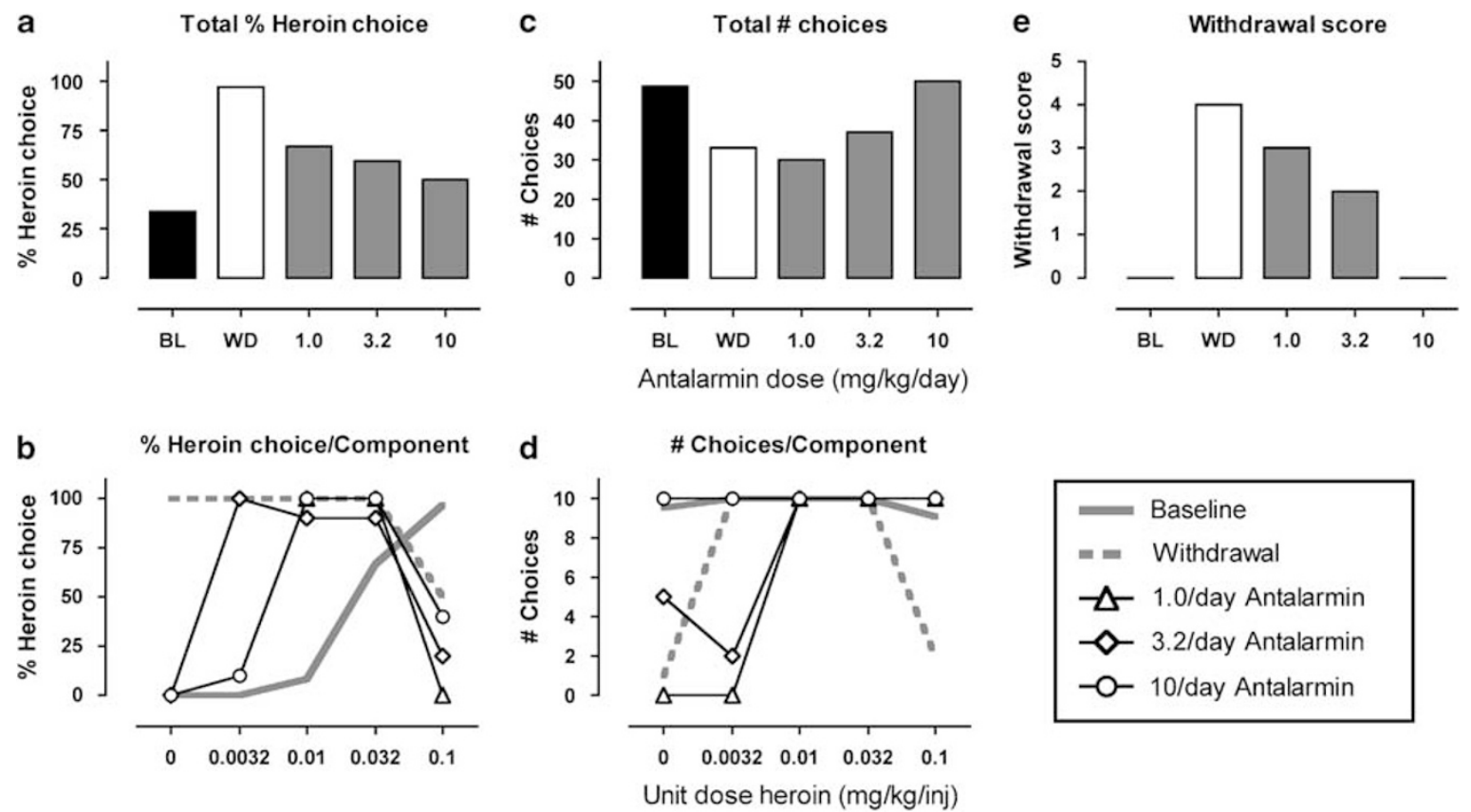

Figure 6 Effects of antalarmin treatment (1.0-10 mg/kg per day) during heroin withdrawal in monkey RQ2393. All details as in Figure 5.
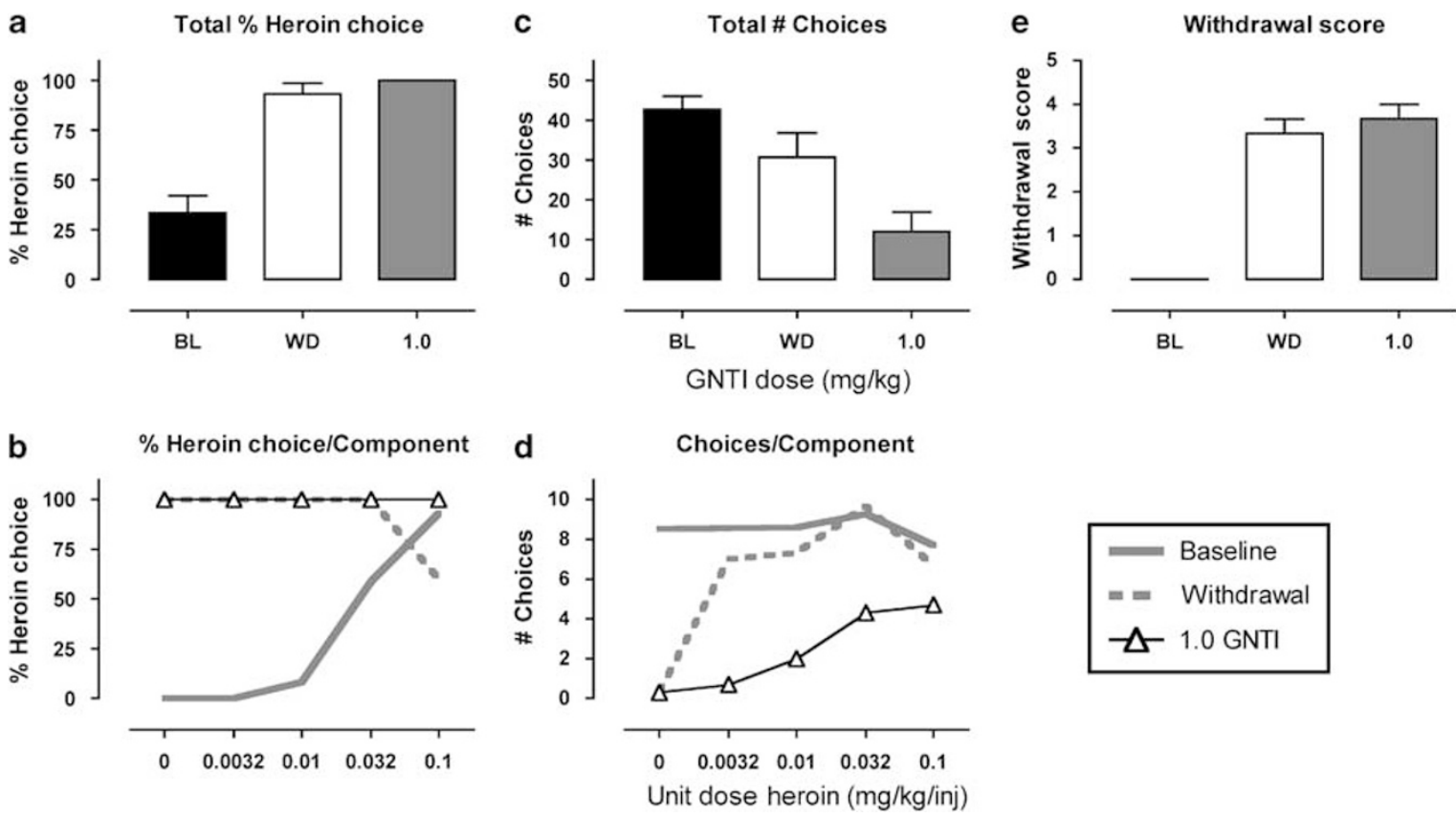

Figure 7 Effects of GNTI treatment $(1.0 \mathrm{mg} / \mathrm{kg}$ ) during heroin withdrawal. Abscissae (top panels): dose GNTI in mg/kg. All panels show mean data in three monkeys. A t-test was used to compare data for GNTI with 'WD' in (a), (c) and (e), and there was not a significant effect of GNTI on any measure ( $p>0.05)$. All other details as in Figure 2.

\section{Effects of Withdrawal on Heroin vs Food Choice}

In the present study, 21-h withdrawal from self-administered heroin produced a robust increase in choice of heroin over food. As we have noted previously, this choice procedure measures the relative reinforcing effects of heroin in comparison with food and not the absolute reinforcing efficacy of heroin (Negus, 2006). Withdrawal from $\mu$-opioid agonists is well known to decrease responding maintained by such non-opioid reinforcers as food, sex, and electrical brain stimulation (Spragg, 1940; Thompson and Schuster, 1964; Schaefer and Michael, 1983), and withdrawal-associated increases in heroin $v s$ food choice could reflect decreases in the reinforcing efficacy of food rather than, or in addition to, changes in the reinforcing efficacy of heroin. Either way, though, opioid withdrawal appears to have the net effect of changing an organism's sensitivity to opioid and non-opioid reinforcers, and thereby channeling behavior toward opioid self-administration. Medications that normalize sensitivity to opioid $v s$ 
non-opioid reinforcers may be useful in the treatment of opioid dependence.

\section{Effects of Morphine}

In the present study, morphine produced a dose-dependent and complete suppression of both somatic withdrawal signs and withdrawal-associated increases in heroin choice. This agrees with previous reports that withdrawal-associated increases in morphine or heroin self-administration can be fully suppressed by treatment with relatively high-efficacy $\mu$-agonists, including morphine, heroin, and methadone, and partially suppressed by treatment with the lower efficacy $\mu$-agonist buprenorphine (Thompson and Schuster, 1964; Griffiths et al, 1975; Griffiths et al, 1981; Negus, 2006). Conversely, the opioid antagonists naloxone and naltrexone precipitate an increase in heroin choice in non-withdrawn, heroin-dependent monkeys (Griffiths et al, 1981; Negus, in press). The efficacy-dependent effects of $\mu$-receptor ligands on opioid self-administration in opioid-dependent monkeys correlates well with the efficacy-dependent ability of these same ligands to suppress or precipitate somatic withdrawal signs (eg Woods and Gmerek, 1985). This correspondence suggests that withdrawal-associated increases in the relative reinforcing efficacy of opioid agonists can be considered as one of a constellation of opioid withdrawal signs, and we have argued that withdrawal effects on opioid reinforcement and opioid self-administration may be especially important in the generation of addictive patterns of drug use. The main purpose of the present study was to evaluate potential mechanisms of withdrawal-associated increases in opioid self-administration using non- $\mu$-opioid pharmacologic tools that have been reported to modulate other signs of opioid withdrawal.

\section{Effects of Catecholaminergic Drugs}

Opioid withdrawal increases norepinephrine release from brain stem noradrenergic neurons and decreases dopamine release from mesolimbic dopamine neurons, and these effects on noradrenergic and dopaminergic systems have been differentially implicated in the expression of different withdrawal signs (Koob and Le Moal, 2001). In the present study, the $\alpha-2$ noradrenergic receptor agonist clonidine failed to suppress withdrawal-associated increases in heroin choice. Insofar as clonidine suppresses withdrawal-induced increases in norepinephrine release, these results suggest that noradrenergic systems do not contribute to withdrawal-associated increases in opioid self-administration. This agrees with previous findings that clonidine also failed to alter the discriminative stimulus effects of opioid withdrawal in animals (Gellert and Holtzman, 1979; France and Woods, 1989) or the craving and other subjective effects elicited by withdrawal in humans (Jasinski et al, 1985; Walsh et al, 2003). However, these findings contrast with reports that administration of clonidine or the related $\alpha-2$ agonist ST-91 in rats attenuated acquisition of withdrawal-induced place aversions (Schulteis et al, 1998; Delfs et al, 2000) and withdrawal-induced suppression of responding maintained by food or electrical brain stimulation (Sparber and Meyer, 1978; Schaefer and Michael, 1983). This dissociation in clonidine effects is illustrative of data supporting the proposition that different withdrawal signs are mediated by different neurobiological mechanisms. Moreover, these results suggest that medication effects on withdrawal-induced increases in opioid selfadministration cannot be reliably predicted by assessment of drug effects on other somatic, mood-related, or motivational effects of withdrawal, despite the presumption that attenuation of these effects may function as a negative reinforcer.

Clonidine also failed to significantly reduce the somatic withdrawal signs monitored in the present study, and at first glance, this would appear to contrast with previous reports that clonidine attenuated somatic/autonomic withdrawal signs in rodents, rhesus monkeys, and humans (Tseng et al, 1975; Gold et al, 1979; Jasinski et al, 1985; Katz, 1986; Sell and France, 2002). However, closer inspection of these earlier studies reveals that clonidine attenuated only a subset of the many different withdrawal signs that have been evaluated, and that in some cases, clonidine effects on these signs were not monotonically related to dose. For example, the most commonly observed withdrawal signs in the present study were 'vocalization,' 'lying on side,' and 'lethargic response to investigator.' In a previous study that provided a more detailed assessment of somatic withdrawal signs in group-housed rhesus monkeys, clonidine also had no effect on 'vocalization,' and clonidine effects on 'lying on side' and 'cooperativity' were small and biphasic (Katz, 1986). Moreover, some effects of withdrawal (eg 'lethargic response to investigator') could not be easily dissociated from the sedative effects produced by clonidine. Lastly, clinical studies have found that clonidine has been most effective in reducing such withdrawal signs as lacrimation, rhinorrhea, and diaphoresis (Greenstein et al, 1997), but these signs were not monitored in the present study. Overall, then, the somatic withdrawal signs monitored in the present study appear to be among those that are either relatively insensitive to suppression by clonidine or similar to the direct effects of clonidine.

It is also important to note that the failure of clonidine to modulate withdrawal signs in this study was not due to insufficient clonidine dosing or insensitivity of the procedures to all treatments. Regarding clonidine dose, clonidine was tested up to doses that produced overt sedation and decreases in response rates and numbers of choices completed. Regarding sensitivity of the procedure, as noted above, morphine produced a dose-dependent and complete suppression of both withdrawal-associated increases in heroin choice and somatic withdrawal signs. Thus, clonidine was ineffective under conditions in which morphine was fully effective.

The dopamine/norepinephrine releaser amphetamine also failed to produce a reliable suppression of withdrawalassociated increases in heroin choice. Although heroin choice was reduced in one monkey during treatment with the highest amphetamine dose, the allocation of responding was erratic and not monotonically related to heroin dose. Thus, even in this monkey, the effects of amphetamine were different from those of morphine. Overall, the relative failure of amphetamine to alter withdrawal-associated increases in heroin choice contrasts with the finding that amphetamine and the monoamine uptake blocker cocaine completely reversed the discriminative stimulus effects of 
morphine withdrawal in rhesus monkeys (Sell and France, 2002; McMahon et al, 2004). Cocaine has also been reported to decrease some opioid withdrawal signs in humans (Kosten and Kosten, 1989; Rosen et al, 1992). Taken together, these differential effects of amphetamine provide intriguing evidence for a dissociation in mechanisms that mediate the discriminative/subjective effects of withdrawal (hypothesized to involve a dopaminergic component; Sell and France, 2002) and the effects of withdrawal on reinforcing efficacy of opioid agonists (perhaps independent of dopamine). This possibility is further supported by data suggesting that opioid self-administration may not rely on dopaminergic substrates in non-dependent animals (Koob et al, 1986). However, amphetamine is not selective in producing dopamine $v s$ norepinephrine release (Rothman et al, 2001), and it is possible that any impact of amphetamine's dopaminergic effects on heroin choice was obscured by its noradrenergic effects (eg a potential exacerbation of autonomic withdrawal signs; Sell et al, 2005). Future studies with more selective indirect or direct dopamine agonists would be useful for addressing this issue (eg Chartoff et al, 2006).

\section{Effects of Antalarmin and GNTI}

In addition to its effects on catecholaminergic systems, chronic opioid exposure also activates systems that employ the neurotransmitters CRF (Iredale et al, 2000; Skelton et al, 2007) and dynorphin (Rattan et al, 1992; Nylander et al, 1995), and it has been proposed that increased activity in CRF and/or dynorphinergic systems may contribute to aversive states of withdrawal and enhanced reinforcing effects of opioid agonists (Koob and Le Moal, 2001). In the present study, the $\kappa$-agonist GNTI failed to suppress withdrawal-associated increases in heroin choice in any of the monkeys, and the CRF1 receptor antagonist antalarmin was ineffective in two of the three monkeys tested. Both drugs were tested up to doses that produced selective $\kappa$ opioid or CRF1 receptor antagonist effects in monkeys in other procedures (Negus et al, 2002; Broadbear et al, 2004). Consequently, the present results do not support a general role for $\kappa$-opioid or CRF systems in mediation of withdrawal-induced enhancement of the relative reinforcing efficacy of opioid agonists.

As a caveat to this general conclusion, it should be noted that antalarmin did produce a dose-dependent, replicable, and morphine-like suppression of both withdrawal-associated increases in heroin choice and somatic signs in one of three monkeys tested. This result provides partial support for a role of CRF1 receptors in mediating signs of opioid withdrawal, and it agrees with previous findings that CRF1 receptor antagonists attenuated both somatic withdrawal signs (Brugger et al, 1998; Iredale et al, 2000; Lu et al, 2000; Skelton et al, 2007) and withdrawal-induced place aversions (Heinrichs et al, 1995; Stinus et al, 2005) in rats. The reason for individual differences in effects of antalarmin in the present study is not clear; however, the morphine-like effects of antalarmin in this subject suggest that CRF systems may contribute to opioid withdrawal in rhesus monkeys under at least some conditions. Future studies will be required to explore this issue further.

\section{Limitations of the Present Study}

The results of the present study suggest that withdrawalassociated increases in opioid reinforcement may be mediated by mechanisms different from or more extensive than those that mediate other somatic, mood-related, and motivational withdrawal signs. However, this study was constrained by several limitations, and the results should be interpreted with appropriate caution. First, this study examined effects of withdrawal from only one level of self-administered heroin. However, it is possible that different mechanisms may be recruited at different levels of opioid dependence produced by shorter/longer access to lower/higher doses of heroin. Second, this study examined choice between heroin and food under conditions in which heroin and food were available under different response requirements (FR 10 and FR 100, respectively). These ratio values were selected to produce a transition from food to heroin choice at an intermediate heroin dose of $0.032 \mathrm{mg} / \mathrm{kg}$ per injection under baseline conditions, and thereby to permit detection of both leftward and rightward shifts in heroin choice dose-effect curves. However, preference between two commodities can vary as function of ratio value (Williams and Woods, 2000; Hursh and Silberberg, 2008), and future studies will be required to explore the degree to which the present results generalize to choice under other response requirements. Third, this study evaluated drug effects in small groups of only three to four adult male rhesus monkeys. Additional studies will also be required to assess the degree to which these results might generalize to larger groups, or to subjects that differ in such attributes as sex, age, strain, or species. Finally, the present study examined effects of four non- $\mu$-opioids administered alone, and the relative ineffectiveness of these compounds suggests that isolated modulation of their target neurotransmitter systems is not sufficient to prevent withdrawalassociated increases in opioid reinforcement. However, it remains possible that these systems contribute in some integrative way to withdrawal effects on opioid selfadministration, and as a result, combination of treatments targeting these (and/or other) neurotransmitter systems may be more effective than any one non- $\mu$-opioid medication alone in preventing withdrawal-associated increases in the relative reinforcing efficacy of opioid agonists.

\section{ACKNOWLEDGEMENTS}

We thank Peter Fivel, Ashley Bear, and Annie Mills for outstanding technical support and Kevin Costa for writing the computer programs used in this study.

\section{DISCLOSURE/CONFLICT OF INTEREST}

The authors declare that this work was funded exclusively from NIH grants RO1-DA02519 and P01-DA14528 from the National Institute on Drug Abuse, and by the Intramural Research Programs of the National Institute on Drug Abuse and the National Institute on Alcohol Abuse and Alcoholism, NIH.

During the past 3 years, Professor Negus has received compensation as a consultant for or collaborator with the pharmaceutical companies Alkermes, Bristol-Myers-Squibb, 
Grunenthal, Limerick, and Vertex for projects generally related to opioid pharmacology or assessment of abuse liability. The present study was not related to any of these professional relationships.

Rice declares that, except for income received from his primary employer, no financial support or compensation has been received from any individual or corporate entity over the past 3 years for research or professional service and there are no personal financial holdings that could be perceived as constituting a potential conflict of interest.

\section{REFERENCES}

Acquas E, Carboni E, Di Chiara G (1991). Profound depression of mesolimbic dopamine release after morphine withdrawal in dependent rats. Eur J Pharmacol 193: 133-134.

Aghajanian GK (1982). Central noradrenergic neurons: a locus for the functional interplay between alpha-2 adrenoceptors and opiate receptors. J Clin Psychiatry 43: 20-24.

Ator NA, Griffiths RR (2003). Principles of drug abuse liability assessment in laboratory animals. Drug Alcohol Depend 70: S55-S72.

Blasig J, Herz A (1977). Precipitated morphine withdrawal in rats as a tool in opiate research. Curr Dev Psychopharmacol 4: 129-149.

Broadbear JH, Winger G, Rivier JE, Rice KC, Woods JH (2004). Corticotropin-releasing hormone antagonists, astressin $\mathrm{B}$ and antalarmin: differing profiles of activity in rhesus monkeys. Neuropsychopharmacology 29: 1112-1121.

Brugger S, Sanchez R, Brugger AJ, Martinez JA (1998). ICV administration of CRF blocker (CRF9-41 delta helical) reduces morphine withdrawal in rats. Prog Neuropsychopharmacol Biol Psychiatry 22: 775-785.

Carrera MR, Schulteis G, Koob GF (1999). Heroin self-administration in dependent Wistar rats: increased sensitivity to naloxone. Psychopharmacology (Berl) 144: 111-120.

Chartoff EH, Mague SD, Barhight MF, Smith AM, Carlezon Jr WA (2006). Behavioral and molecular effects of dopamine D1 receptor stimulation during naloxone-precipitated morphine withdrawal. J Neurosci 26: 6450-6457.

Criner SH, Liu J, Schulteis G (2007). Rapid neuroadaptation in the nucleus accumbens and bed nucleus of the stria terminalis mediates suppression of operant responding during withdrawal from acute opioid dependence. Neuroscience 144: 1436-1446.

Delfs JM, Zhu Y, Druhan JP, Aston-Jones G (2000). Noradrenaline in the ventral forebrain is critical for opiate withdrawal-induced aversion. Nature 403: 430-434.

France CP, Woods JH (1989). Discriminative stimulus effects of naltrexone in morphine-treated rhesus monkeys. J Pharmacol Exp Ther 250: 937-943.

Frenois F, Cador M, Caille S, Stinus L, Le Moine C (2002). Neural correlates of the motivational and somatic components of naloxone-precipitated morphine withdrawal. Eur J Neurosci 16: 1377-1389.

Gellert VF, Holtzman SG (1979). Discriminative stimulus effects of naltrexone in the morphine-dependent rat. J Pharmacol Exp Ther 211: 596-605.

Gold MS, Redmond Jr DE, Kleber HD (1979). Noradrenergic hyperactivity in opiate withdrawal supported by clonidine reversal of opiate withdrawal. Am J Psychiatry 136: 100-102.

Greenstein RA, Fudala PJ, O'Brien CP (1997). Alternative pharmacotherapies for opiate addiction. In: Lowinson $\mathrm{JH}$, Ruiz P, Millman RB and Langrod JG (eds). Substance Abuse: A Comprehensive Textbook. Williams and Wilkins: Baltimore. pp 415-425.
Griffiths RR, Wurster RM, Brady JV (1975). Discrete-trial choice procedure: effects of naloxone and methadone on choice between food and heroin. Pharmacol Rev 27: 357-365.

Griffiths RR, Wurster RM, Brady JV (1981). Choice between food and heroin: effects of morphine, naloxone, and secobarbital. J Exp Anal Behav 35: 335-351.

Heinrichs SC, Menzaghi F, Schulteis G, Koob GF, Stinus L (1995). Suppression of corticotropin-releasing factor in the amygdala attenuates aversive consequences of morphine withdrawal. Behav Pharmacol 6: 74-80.

Hursh SR, Silberberg A (2008). Economic demand and essential value. Psychol Rev 115: 186-198.

Iredale PA, Alvaro JD, Lee Y, Terwilliger R, Chen YL, Duman RS (2000). Role of corticotropin-releasing factor receptor-1 in opiate withdrawal. J Neurochem 74: 199-208.

Jasinski DR, Johnson RE, Kocher TR (1985). Clonidine in morphine withdrawal. Differential effects on signs and symptoms. Arch Gen Psychiatry 42: 1063-1066.

Katz JL (1986). Effects of clonidine and morphine on opioid withdrawal in rhesus monkeys. Psychopharmacology (Berl) 88: 392-397.

Koob GF, Ahmed SH, Boutrel B, Chen SA, Kenny PJ, Markou A et al (2004). Neurobiological mechanisms in the transition from drug use to drug dependence. Neurosci Biobehav Rev 27: 739-749.

Koob GF, Le Moal M (2001). Drug addiction, dysregulation of reward, and allostasis. Neuropsychopharmacology 24: 97-129.

Koob GF, Vaccarino FJ, Amalric M, Bloom FE (1986). Neurochemical substrates for opiate reinforcement. NIDA Res Monogr 71: 146-164.

Kosten TA, Kosten TR (1989). Cocaine abuse and opioid withdrawal. Lancet 2: 165-166.

Lu L, Liu D, Ceng X, Ma L (2000). Differential roles of corticotropin-releasing factor receptor subtypes 1 and 2 in opiate withdrawal and in relapse to opiate dependence. Eur $J$ Neurosci 12: 4398-4404.

Maldonado R, Negus S, Koob GF (1992a). Precipitation of morphine withdrawal syndrome in rats by administration of mu-, delta- and kappa-selective opioid antagonists. Neuropharmacology 31: 1231-1241.

Maldonado R, Stinus L, Gold LH, Koob GF (1992b). Role of different brain structures in the expression of the physical morphine withdrawal syndrome. J Pharmacol Exp Ther 261: 669-677.

McMahon LR, Sell SL, France CP (2004). Cocaine and other indirect-acting monoamine agonists differentially attenuate a naltrexone discriminative stimulus in morphine-treated rhesus monkeys. J Pharmacol Exp Ther 308: 111-119.

Mello NK (2005). Fischman Memorial Lecture. Evaluation of drug abuse treatment medications: concordance between clinical and preclinical studies. NIDA Res Monogr 185: 82-104.

Mello NK, Negus SS, Rice KC, Mendelson JH (2006). Effects of the CRF1 antagonist antalarmin on cocaine self-administration and discrimination in rhesus monkeys. Pharmacol Biochem Behav 85: 744-751.

Negus SS (2003). Rapid assessment of choice between cocaine and food in rhesus monkeys: effects of environmental manipulations and treatment with D-amphetamine and flupenthixol. Neuropsychopharmacology 28: 919-931.

Negus SS (2005). Interactions between the reinforcing effects of cocaine and heroin in a drug- $v s$-food choice procedure in rhesus monkeys: a dose-addition analysis. Psychopharmacology (Berl) 180: $115-124$.

Negus SS (2006). Choice between heroin and food in nondependent and heroin-dependent rhesus monkeys: effects of naloxone, buprenorphine, and methadone. J Pharmacol Exp Ther 317: 711-723.

Negus SS. Opioid antagonist effects in animal models related to opioid abuse: drug discrimination and drug self-administration. 
In: Dean R, Bilsky EJ, Negus SS (eds). Opioid Receptors and Antagonists: From Bench to Clinic. Humana Press: New York, NY. (in press)

Negus SS, Mello NK (2002). Effects of mu-opioid agonists on cocaine- and food-maintained responding and cocaine discrimination in rhesus monkeys: role of mu-agonist efficacy. J Pharmacol Exp Ther 300: 1111-1121.

Negus SS, Mello NK (2004). Effects of chronic methadone treatment on cocaine- and food-maintained responding under second-order, progressive-ratio and concurrent-choice schedules in rhesus monkeys. Drug Alcohol Depend 74: 297-309.

Negus SS, Mello NK, Linsenmayer DC, Jones RM, Portoghese PS (2002). Kappa opioid antagonist effects of the novel kappa antagonist $5^{\prime}$-guanidinonaltrindole (GNTI) in an assay of schedule-controlled behavior in rhesus monkeys. Psychopharmacology (Berl) 163: 412-419.

Nylander I, Vlaskovska M, Terenius L (1995). The effects of morphine treatment and morphine withdrawal on the dynorphin and enkephalin systems in Sprague-Dawley rats. Psychopharmacology (Berl) 118: 391-400.

O'Brien CP (2006). Drug addiction and drug abuse. In: Brunton L, Lazo J, Parker K (eds). The Pharmacological Basis of Therapeutics. McGraw-Hill: New York. pp 607-628.

Rattan AK, Koo KL, Tejwani GA, Bhargava HN (1992). The effect of morphine tolerance dependence and abstinence on immunoreactive dynorphin (1-13) levels in discrete brain regions, spinal cord, pituitary gland and peripheral tissues of the rat. Brain Res 584: 207-212.

Redmond Jr DE, Huang YH (1982). The primate locus coeruleus and effects of clonidine on opiate withdrawal. J Clin Psychiatry 43: 25-29.

Rosen MI, Wallace EA, Sullivan MC, Stine S, Kosten TR (1992). Use of cocaine to prevent opiate withdrawal. Am J Psychiatry 149: 1609.

Rothman RB, Baumann MH, Dersch CM, Romero DV, Rice KC, Carroll FI et al (2001). Amphetamine-type central nervous system stimulants release norepinephrine more potently than they release dopamine and serotonin. Synapse 39: 32-41.

Schaefer GJ, Michael RP (1983). Morphine withdrawal produces differential effects on the rate of lever-pressing for brain selfstimulation in the hypothalamus and midbrain in rats. Pharmacol Biochem Behav 18: 571-577.

Schulteis G, Stinus L, Risbrough VB, Koob GF (1998). Clonidine blocks acquisition but not expression of conditioned opiate withdrawal in rats. Neuropsychopharmacology 19: 406-416.

Seevers MH, Deneau GA (1963). Physiological aspects of tolerance and dependence. In: Root WS and Hofmann FG (eds). Physiological Pharmacology I. Academic Press: New York. pp 565-640.
Sell SL, France CP (2002). Cocaine and amphetamine attenuate the discriminative stimulus effects of naltrexone in opioid-dependent rhesus monkeys. J Pharmacol Exp Ther 301: 1103-1110.

Sell SL, McMahon LR, Koek W, France CP (2005). Monoaminergic drugs and directly observable signs of LAAM withdrawal in rhesus monkeys. Behav Pharmacol 16: 53-58.

Skelton KH, Oren D, Gutman DA, Easterling K, Holtzman SG, Nemeroff CB et al (2007). The CRF1 receptor antagonist, R121919, attenuates the severity of precipitated morphine withdrawal. Eur J Pharmacol 571: 17-24.

Sparber SB, Meyer DR (1978). Clonidine antagonizes naloxoneinduced suppression of conditioned behavior and body weight loss in morphine-dependent rats. Pharmacol Biochem Behav 9: 319-325.

Spragg SDS (1940). Morphine addiction in chimpanzees. Comp Psychol Monogr 15: 5-132.

Stinus L, Cador M, Zorrilla EP, Koob GF (2005). Buprenorphine and a CRF1 antagonist block the acquisition of opiate withdrawal-induced conditioned place aversion in rats. Neuropsychopharmacology 30: 90-98.

Stinus L, Le Moal M, Koob GF (1990). Nucleus accumbens and amygdala are possible substrates for the aversive stimulus effects of opiate withdrawal. Neuroscience 37: 767-773.

Tatum AL, Seevers MH, Collins KH (1929). Morphine addiction and its physiological interpretation based on experimental evidences. J Pharmacol 36: 447-475.

Thompson T, Schuster CR (1964). Morphine self-administration, food-reinforced, and avoidance behaviors in rhesus monkeys. Psychopharmacologia 5: 87-94.

Tseng LF, Loh HH, Wei ET (1975). Effects of clonidine on morphine withdrawal signs in the rat. Eur J Pharmacol 30: 93-99.

Van Bockstaele EJ, Qian Y, Sterling RC, Page ME (2008). Low dose naltrexone administration in morphine dependent rats attenuates withdrawal-induced norepinephrine efflux in forebrain. Prog Neuropsychopharmacol Biol Psychiatry 32: 1048-1056.

Walker BM, Koob GF (2008). Pharmacological evidence for a motivational role of kappa-opioid systems in ethanol dependence. Neuropsychopharmacology 33: 643-652.

Walsh SL, Strain EC, Bigelow GE (2003). Evaluation of the effects of lofexidine and clonidine on naloxone-precipitated withdrawal in opioid-dependent humans. Addiction 98: 427-439.

Williams KL, Woods JH (2000). A behavioral economic analysis of concurrent ethanol- and water-reinforced responding in different preference conditions. Alcohol Clin Exp Res 24: 980-986.

Woods JH, Gmerek DE (1985). Substitution and primary dependence studies in animals. Drug Alcohol Depend 14: 233-247.

Yanagita T (1978). Drug dependence studies in laboratory animals. NIDA Res Monogr 19: 179-190. 